\title{
Calculation of Ozone and NOx Production under AC Corona Discharge in Dry Air Used for Faults Diagnostic
}

\author{
Kang $\mathrm{Li}^{1, \mathrm{a}}$, Hassan Javed ${ }^{1, \mathrm{~b}}$, Guoqiang Zhang ${ }^{1, \mathrm{c}}$ \\ ${ }^{1}$ Institute of Electrical Engineering, Chinese Academy of Sciences, Beijing, 100190, China \\ aemail: likang07@mail.iee.ac.cn, ${ }^{b}$ email:Hassan@mail.iee.ac.cn, ${ }^{\star c}$ email:zhanggqi@mail.iee.ac.cn
}

Keywords: Ozone Production; NOx Production; AC Corona Discharge

\begin{abstract}
Air is one of the most widely used insulation medium in power systems. However, up to now there is no any existing quantitative gas analysis method used for fault diagnostic based on air by-products detection and analysis. In this paper, a new discharge diagnostic method — gas analysis method based on air by-products (ozone and $\mathrm{NO}_{\mathrm{x}}$ ) is proposed. The feasibility of this method is studied in this paper. Firstly, the chemical reaction of air under discharge is analyzed; then a typical partial discharge — protrusion defect discharge is simulated based on electron induced chemical reaction and chemical kinetics. The reaction models are built using differential equation and solved using Runge-Kutta method. The density of $\mathrm{O}_{3}$ and $\mathrm{NO}_{\mathrm{x}}$ is obtained near needle tip under different discharge and air condition. The results show there are detectable $\mathrm{O}_{3}$ and $\mathrm{NO}_{\mathrm{x}}$ generated even when discharge capacity is only $5 \mathrm{pC}$. Meanwhile, when discharge capacity is less than $100 \mathrm{pC}$ the production of $\mathrm{O}_{3}$ and $\mathrm{NO}_{\mathrm{x}}$ are in the same order. When discharge capacity increases, the production of $\mathrm{O}_{3}$ becomes the main by-product. $\mathrm{NO}_{\mathrm{x}}$ is less than $1 \%$ of $\mathrm{O}_{3}$ when discharge capacity is about $10000 \mathrm{pC}$. The density of $\mathrm{O}_{3}$ increases linearly with discharge strength and density. Both gas temperature T and pressure $\mathrm{P}$ have little impact on the density of $\mathrm{O}_{3}$ and $\mathrm{NO}_{\mathrm{x}}$ in calculated ranges. However the $[\mathrm{NO}] /\left[\mathrm{NO}_{2}\right]$ does decrease as $\mathrm{P}$ and $\mathrm{T}$ increases. These properties imply gas analysis method is a potential method to detect discharge faults.
\end{abstract}

\section{Introduction}

Chemical detect method also called decomposition gas analysis method is widely used in power system to monitor the discharge faults in electrical equipment, having the advantages to be not invasive, not affected by unwanted electrical disturbances. For example, when discharge or overheat happening, the transformer oil will decomposes to small molecules such as $\mathrm{H}_{2}, \mathrm{CH}_{4}$, $\mathrm{C} 2 \mathrm{H} 4$, and $\mathrm{C}_{2} \mathrm{H}_{6}$. And a fault diagnostic method which is called dissolved gas analysis (DGA) is based on detection of these molecules [1]. DGA is one of the most effective method to diagnostic the faults in oil insulated apparatus, especially transformers. Based on this method, one can know the operating condition of the equipment and which kind of faults is happening. For $\mathrm{SF}_{6}$ insulted apparatus, a similar method is also exist [2]. Air is the most widely used insulation material; however there is few study on fault diagnostic method based on the air derivatives such as ozone $\left(\mathrm{O}_{3}\right), \mathrm{NO}_{\mathrm{x}}$. One knows that there is $\mathrm{O}_{3}$ and other chemical molecules generated under discharge, but few do more research on this. L.Lepine and D.N.Nguyen from Canada measured the ozone distribution inside stator core of an air-cooled hydro-generator and shows ozone measurement can be used to locate partial discharge qualitatively [3][4]. But no intensive study is done both at home and abroad. Besides, a lot of work has been done on $\mathrm{O}_{3}$ generation by gas discharge [5-9]. And many researchers study the $\mathrm{O}_{3}$ production under different kinds of discharge. However, as we know no one has focus on faults diagnostic of electrical equipment.

In this paper, a typical corona discharge pattern-protrusion defect discharge is simulated based on the electron induced chemical reaction and chemical kinetics. By solving differential equations describing the process step by step the total $\mathrm{O}_{3}$ and $\mathrm{NO}_{x}$ production are obtained. Meanwhile, the influence of discharge strength and density, air temperature and pressure are studied. The results imply gas analysis method in air similarly with gas analysis in $\mathrm{SF}_{6}$ is a potential method to detect corona discharge of electrical apparatus happening in air. 


\section{Generation of Ozone and NOx under Corona Discharge}

A lot of research has been done on how to effectively generate ozone which is used in ozone generator. In these studies, the mechanism of ozone generation in silent discharge of oxygen-fed and air-fed ozonisers are studied [5][6]. As the main process is show as in table 1. Here we need to note that this is just one of many mechanisms which include only the main reactions.

Tab.1 Chemical model of by-product generation during corona discharge

\begin{tabular}{lll||lll}
\hline Serial No. & Chemical Reaction & Reaction rate constant & Serial No. & Chemical Reaction & Reaction rate constant \\
\hline R1 & $\mathrm{e}+\mathrm{O}_{2} \rightarrow \mathrm{O}+\mathrm{O}+\mathrm{e}$ & $\mathrm{k}_{1 \mathrm{e}}$ & $\mathrm{R} 8$ & $\mathrm{O}+\mathrm{NO}_{2} \rightarrow \mathrm{NO}+\mathrm{O}_{2}$ & $\mathrm{k}_{8}=1.7^{*} 10^{-11} \mathrm{e}^{(-300 / \mathrm{T})}$ \\
$\mathrm{R} 2$ & $\mathrm{O}+\mathrm{O}_{2}+\mathrm{M} \rightarrow \mathrm{O}_{3}+\mathrm{M}$ & $\mathrm{k}_{2}=1.06 * 10^{-35} \mathrm{e}^{(510 / \mathrm{T})}$ & $\mathrm{R} 9$ & $\mathrm{NO}+\mathrm{O}_{3} \rightarrow \mathrm{NO}_{2}+\mathrm{O}_{2}$ & $\mathrm{k}_{9}=1.5^{*} 10^{-12} \mathrm{e}^{(-1300 / \mathrm{T})}$ \\
$\mathrm{R} 3$ & $\mathrm{O}+\mathrm{O}_{3} \rightarrow \mathrm{O}_{2}+\mathrm{O}_{2}$ & $\mathrm{k}_{3}=1.9 * 10^{-11} \mathrm{e}^{(-2300 / \mathrm{T})}$ & $\mathrm{R} 10$ & $\mathrm{NO}_{2}+\mathrm{O}_{3} \rightarrow \mathrm{NO}_{3} \mathrm{O}_{2}$ & $\mathrm{k}_{10}=1.2^{*} 10^{-13} \mathrm{e}^{(-2450 / \mathrm{T})}$ \\
$\mathrm{R} 4$ & $\mathrm{e}+\mathrm{O}_{3} \rightarrow \mathrm{O}_{2}+\mathrm{O}$ & $\mathrm{k}_{4 \mathrm{e}}$ & $\mathrm{R} 11$ & $\mathrm{NO}+\mathrm{NO}_{3} \rightarrow 2 \mathrm{NO}_{2}$ & $\mathrm{k}_{11}=8.7 * 10^{-12}$ \\
R5 & $\mathrm{e}+\mathrm{N}_{2} \rightarrow \mathrm{N}+\mathrm{N}+\mathrm{e}$ & $\mathrm{k}_{5}$ & $\mathrm{R} 12$ & $\mathrm{NO}_{2}+\mathrm{NO}_{3} \rightarrow \mathrm{N}_{2} \mathrm{O}_{5}$ & $\mathrm{k}_{12}=3.8^{*} 10^{-12}$ \\
R6 & $\mathrm{N}+\mathrm{O}_{2} \rightarrow \mathrm{NO}+\mathrm{O}$ & $\mathrm{k}_{6}=1.1^{*} 10^{-14} \mathrm{Te}(-3150 / \mathrm{T})$ & $\mathrm{R} 13$ & $\mathrm{~N}_{2} \mathrm{O}_{5} \rightarrow \mathrm{NO}_{2}+\mathrm{NO}_{3}$ & $\mathrm{k}_{13}=5.7^{*} 10^{14} \mathrm{e}^{(-10600 / \mathrm{T})}$ \\
R7 & $\mathrm{N}+\mathrm{O}_{3} \rightarrow \mathrm{NO}+\mathrm{O}_{2}$ & $\mathrm{k}_{7}=5.7 * 10^{-13}$ & $\mathrm{R} 14$ & $\mathrm{O}+\mathrm{N}_{2} \mathrm{O}_{5} \rightarrow 2 \mathrm{NO}_{2}+\mathrm{O}_{2}$ & $\mathrm{k}_{14}=1.5^{*} 10^{-13}$ \\
\hline
\end{tabular}

As said in literature [5][6] the R1and R5 is the initial step involved in the formation of $\mathrm{O}_{3}$ and $\mathrm{NO}_{\mathrm{x}}$. It means the electron density which stands for PD capacity is a key role that influences the production of ozone and $\mathrm{NO}_{\mathrm{x}}$. At the same time, considering the band energy of $\mathrm{O}_{2}$ and $\mathrm{N}_{2}$ the kinetic energy of electrons which stand for discharge intensity will also infect the production or production rate of ozone and $\mathrm{NO}_{\mathrm{x}}$. There are some relations between the concentrations of ozone and $\mathrm{NO}_{\mathrm{x}}$ and discharge parameters. It means the conditions of air by-product may be used to diagnostic the discharge faults of electrical apparatus in air. However, we can also see from table 1 that the $\mathrm{O}_{3}$ and $\mathrm{NO}_{x}$ will interact with each other and the $\mathrm{O}_{3}$ will decompose naturally. Meanwhile, in practical application the gap, temperature, pressure and humanity will affect the gas concentration too. So it will be hard to build the relation between by-products concentration and discharge pattern. And a good knowledge of the physical chemistry reaction would be useful for the building of diagnostic criterion. However, it is hard to study the chemistry reaction by experiment. Simulations are used to determine the changing process.

\section{Simulation Model}

1) Description of Corona Discharge by Needle-Plane Electrodes

Fig.1 illustrates the typical corona discharge between needle-plane electrodes. The needle electrode is connected to the high voltage. The plane electrode is earthed. Free electrons formed naturally in the inter-electrode space are accelerated toward the wire. In the region very near the needle, where the electric field strength is greater than $3 \mathrm{kV} / \mathrm{mm}$, inelastic collisions of electrons and neutral gas molecules produce electron-positive ion pairs. The dissociation rate coefficient of $\mathrm{O}_{2}, \mathrm{~N}_{2}$ and $\mathrm{O}_{3}$ by electron impact depends on the energy distribution of electrons in the silent discharge. In the paper these coefficients are treated as functions of the electric field strength per unit gas density. Thus the average rate of $\mathrm{O}$ atom formation by (R1) is

$$
\left.\frac{d[O]}{d t}\right|_{R 1}=2 \frac{\chi\left(\mathrm{O}_{2}\right)}{N} v_{d e}[e]\left[O_{2}\right]
$$

Where $\chi\left(\mathrm{O}_{2}\right) / N_{2}$ corresponding to $\mathrm{k}_{1 \mathrm{e}}$ in table 1 , is the dissociation rate coefficient of $\mathrm{O}_{2}$ normalized by the number density $\mathrm{N}$ of air, $v_{d e}$ is the drift velocity of electrons, and [e] and $\left[\mathrm{O}_{2}\right]$ are the average electron number density and the average $\mathrm{O}_{2}$ number density.

[e], the average electron density reflects the discharge density. It can be calculated using conservation equation of charge electrons, positive ions and negative ions and Boltzmann equation. It is complex, inaccurate and unnecessary. In this paper we use the discharge quantity to indicate the electron density. For ac corona discharge the discharge is not stable, it only happens when $|U|$ is 
higher than initial voltage $U c$. The time $T d$ with discharge indicate the discharge intensity. it makes no sense to get average value of [e] in the all period. Meanwhile, we assume there are no electrons generated during this time. However, for each discharge pulse the period $T p$ is about 50 -200us depending on the discharge intensity as measured by PD measurement device, and it is ok to get average value of [e] during discharge period. Then the average electron density [e] expressed in terms of the discharge quantity is:

$$
\left\{\begin{array}{l}
{[e]=\frac{P_{c} \cdot T_{p}}{q_{e} \cdot v_{d e} \cdot T_{p} \cdot S}, U_{c} \leq U} \\
{[e]=0, U<U_{c}}
\end{array}\right.
$$

Where $P_{c}$ is the discharge quantities of each discharge pulse, $q_{e}$ the charge of electron, $U$ is the average electric potential in the electrode, $U_{C}$ is the corona discharge initial voltage; $S$ is the discharge area of electrode.

From equations (2) and (3), when discharge happen the rate of $\mathrm{O}$ atom formation by (R1) is:

$$
\left.\frac{d[O]}{d t}\right|_{R 1}=2 \frac{\chi\left(O_{2}\right)}{N} \frac{P_{c}}{q_{e} \cdot S}\left[O_{2}\right]
$$

Similarly, when discharge happen the rate of $\mathrm{N}$ atom formation by (R5) and $\mathrm{O}$ atom, $\mathrm{O}_{2}$ formation by (R4) are:

$$
\begin{aligned}
& \left.\frac{d[N]}{d t}\right|_{R 5}=2 \frac{\chi\left(N_{2}\right)}{N} \frac{P_{c}}{q_{e} \cdot S}\left[N_{2}\right] \\
& \left.\frac{d[O]}{d t}\right|_{R 4}=\frac{\chi\left(O_{3}\right)}{N} \frac{P_{c}}{q_{e} \cdot S}\left[O_{3}\right] \\
& \left.\frac{d\left[O_{2}\right]}{d t}\right|_{R 4}=\frac{\chi\left(O_{3}\right)}{N} \frac{P_{c}}{q_{e} \cdot S}\left[O_{3}\right]
\end{aligned}
$$

The transportation of molecular is not considered in the above model. The densities of $\mathrm{O}$ and $\mathrm{N}$ atoms produced by the electron collision processes are inhomogeneous. But, as all of the reactions included in the proposed mechanism are of first order with regard to these atoms, the above inhomogeneities are not important in so far as one considers the macroscopic processes of gas production on a time-scale close to the residence time of the gas under the needle electrode. The residence time is defined as an average time of the gas stain under the needle as gas flow through the needle-plane electrodes gap in flow rate $\mathrm{Q}(\mathrm{L} / \mathrm{min})$. So we assume that the electrons induced reactions occur in a small closed region near the needle are homogeneous. The calculated results are only used in small area near the needle with stable discharge. For the gases away from discharge point the electron-impact reaction will not exist. Only chemical reactions are calculated.

2) Description of Chemical Reactions

All the chemistry reactions and corresponding Arrhenius rate coefficients included in the calculation are listed in table 1 . As we can see only gas-phase reactions of neutral species are chose. They include 9 neutral species and 11 reactions. Based on reaction kinetics, the rate of O3 formation by (R2) is:

$$
\left.\frac{d[\mathrm{O} 3]}{d t}\right|_{R 2}=k_{2}[\mathrm{O}]\left[\mathrm{O}_{2}\right][\mathrm{M}]
$$

The rate of $\mathrm{O}$ consumption by (R2) is:

$$
\left.\frac{d[O]}{d t}\right|_{R 2}=-k_{2}[O]\left[O_{2}\right][M]
$$

The formation and consumption of other species can obtain similarly.

Where $\mathrm{M}$ is the third body of three-body reaction, in dry air it is $\mathrm{O}_{2}$ or $\mathrm{N}_{2}$.

3) Initial Conditions

Normally, in dry air as we studied there are some $\mathrm{O}_{3}$ and $\mathrm{NO}_{\mathrm{x}}$ exist. For $\mathrm{O}_{3}$, the concentration is 
about 8ppbv and for $\mathrm{NO}_{\mathrm{x}}, \mathrm{NO}_{2}$ in main is about 20ppbv. The initial concentration of $\mathrm{O}_{2}$ and $\mathrm{N}_{2}$ are 0.21 and 0.78 separately. The yields of other species are set to be 0 . The dissociation rate coefficient of $\mathrm{O}_{2}, \mathrm{O}_{3}$, and $\mathrm{N}_{2}$ is obtained from reference [6]. They are varied a little under different temperature [9]. We assume it is constant from $273 \mathrm{~K}$ to $313 \mathrm{~K}\left(0 \sim 40^{\circ} \mathrm{C}\right)$. The values are list in table 2. The calculation method is verified by comparing the results with the earlier literature [6]. The results show in figure 1.

Tab.2 Dissociation rate coefficient of $\mathrm{O}_{2}, \mathrm{O}_{3}$, and $\mathrm{N}_{2}$

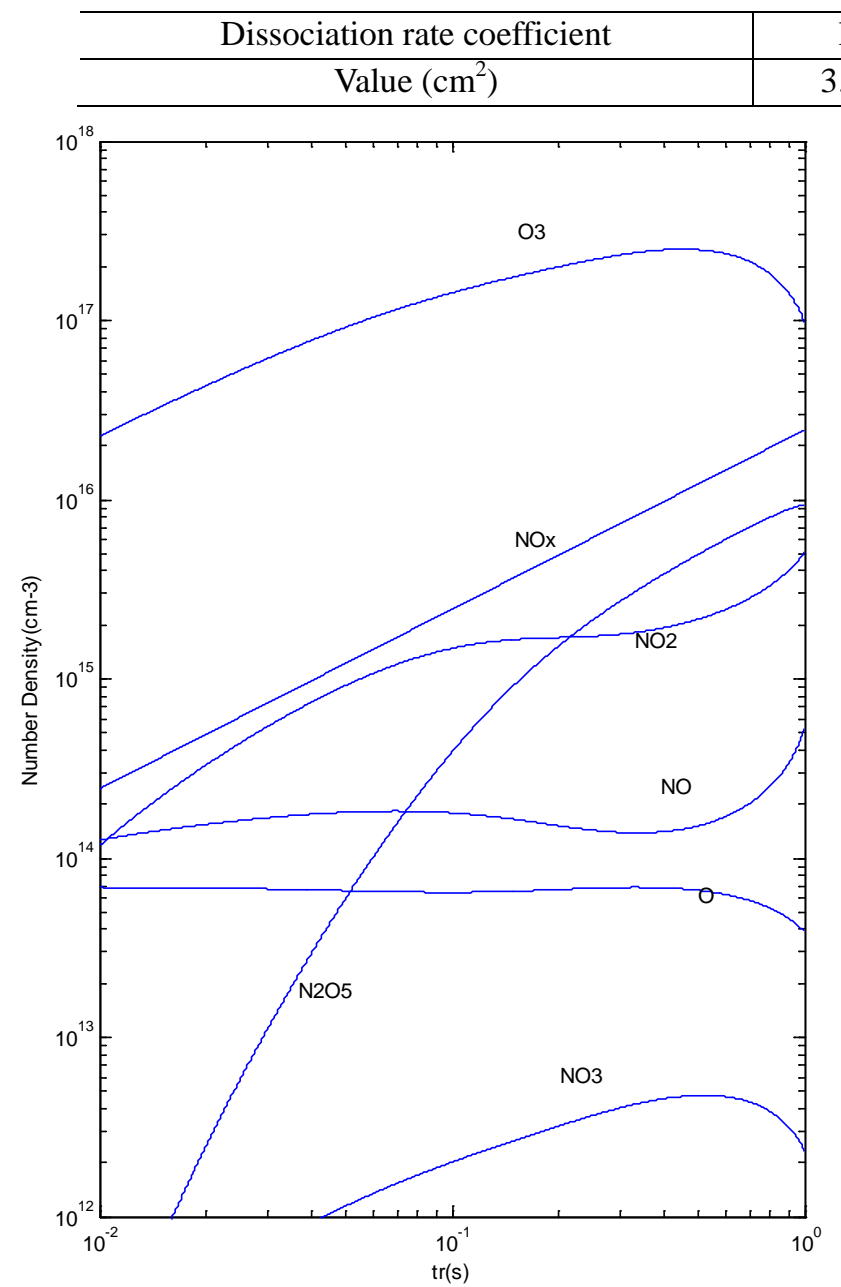

Figure 1. Generation of $\mathrm{O}_{3}$ and $\mathrm{NO}_{\mathrm{x}}$ from dry air under streamer discharge

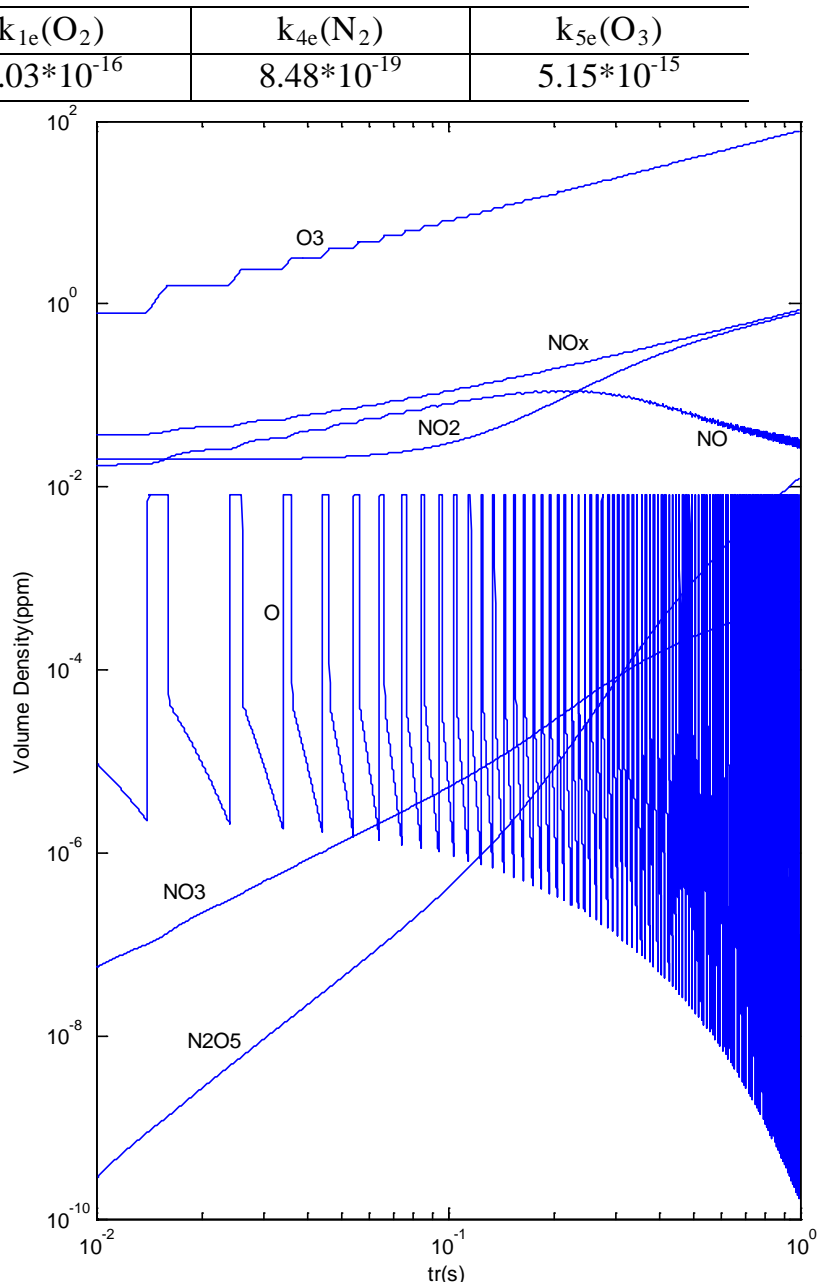

Figure 2. Generation of $\mathrm{O}_{3}$ and $\mathrm{NO}_{x}$ from dry air under corona discharge

\section{Results and Discussion}

1) Generation of $\mathrm{O}_{3}$ and $\mathrm{NO}_{x}$ in Dry Air

The results of calculations of the Volume density of each species are presented as solid curves in figure 2. The discharge parameters assumed in the calculation are listed in table 3.The abscissa of Figure 2 is the residence time tr of the gas in the discharge zone, in here it means the needle tip area, and the ordinate is the species density expressed in volume density ppm.

Tab.3 Discharge parameters of corona discharge

\begin{tabular}{c|c|c|c|c|c}
\hline Parameter & P & T & Pc & Td & S \\
\hline Value & $1 \mathrm{~atm}$ & $293 \mathrm{~K}$ & $10000 \mathrm{pC}$ & $4 \mathrm{~ms}$ & $2 \mathrm{~mm}^{2}$ \\
\hline
\end{tabular}

As we can see from Figure 2 as residence time tr increases the density of most species increase except $\mathrm{O}$ and NO. It indicates that the flow speed of gas near the needle tip is a main character that effects the concentration of species. Meanwhile, the $\mathrm{O}_{3}$ is the main by-product. NOx is little compare to $\mathrm{O}_{3}$ and is less than $1 \%$ of $\mathrm{O}_{3}$. The density of $\mathrm{NO}$ is bigger than $\mathrm{NO}_{2}$ when residence 
time is small. When $t r$ is bigger than about $0.2 \mathrm{~s}, \mathrm{NO}_{2}$ becomes bigger. That is because as chemical reaction continues the $\mathrm{NO}$ transfer to $\mathrm{NO}_{2}$. The square wave indicate the density of $\mathrm{O}$, it clearly reflects the periodicity of $\mathrm{PD}$ under $\mathrm{AC}$ voltage. When there is $\mathrm{PD}$ happens, the density of $\mathrm{O}$ increases; when PD stops, the $\mathrm{O}$ is consumed by R2, R3 etc. The density of $\mathrm{O}$ decreases. The top value of $\mathrm{O}$ is nearly stable. This shows the generation of $\mathrm{O}$ is faster than its consumption in the calculated tr. The main product of $\mathrm{NOx}$ is $\mathrm{NO}$ and $\mathrm{NO}_{2}$. The production of $\mathrm{NO}_{3}$ and $\mathrm{N}_{2} \mathrm{O}_{5}$ are very small compare to NOx especially when residence time is little and are not listed in the following table. The calculation results also show that productions of NOx tell more messages about the reactions.

2) Influence of Discharge strength and density

In this part, the impact of discharge strength and density are studied. The discharge strength Pc is assumed to be $5 \mathrm{pC}, 100 \mathrm{pC}, 500 \mathrm{pC}$ and $1000 \mathrm{pC}$. And the discharge time Td which in here indicates density in each power frequency circle is assumed to be $2 \mathrm{~ms}, 4 \mathrm{~ms}$ and $6 \mathrm{~ms}$. Gas pressure $\mathrm{P}$ and temperature $\mathrm{T}$ are assumed to be $1 \mathrm{~atm}$ and $293 \mathrm{~K}$. The calculated results for residence time tr equal to $1 \mathrm{~s}$ are list in table 4.

Tab.4 Influence of Discharge strength and density to $\mathrm{O}_{3}$ and NOx production

\begin{tabular}{c|c|c|c|c|c|c|c}
\hline Serial No. & $\mathrm{Pc}(\mathrm{pC})$ & $\mathrm{Td}(\mathrm{ms})$ & $\mathrm{cO}_{3}(\mathrm{ppmv})$ & $\mathrm{cNO}_{\mathrm{x}}(\mathrm{ppmv})$ & $\mathrm{cNO}(\mathrm{ppmv})$ & $\mathrm{cNO}_{2}(\mathrm{ppmv})$ & $\mathrm{cNO} / \mathrm{cNO}_{2}$ \\
\hline 1 & 5 & 2 & 0.0160 & 0.0191 & 0.0101 & 0.0090 & 1.12 \\
\hline 2 & 100 & 2 & 0.207 & 0.0211 & 0.0115 & 0.0095 & 1.21 \\
\hline 3 & 500 & 2 & 1.01 & 0.0293 & 0.0169 & 0.0124 & 1.36 \\
\hline 4 & 1000 & 2 & 2.01 & 0.0397 & 0.0220 & 0.0177 & 1.24 \\
\hline 5 & 500 & 4 & 2.00 & 0.0396 & 0.0219 & 0.0177 & 1.24 \\
\hline 6 & 500 & 6 & 2.99 & 0.0499 & 0.0255 & 0.0245 & 1.04 \\
\hline
\end{tabular}

As we can see in tab.4 there are about $16 \mathrm{ppbv}$ of $\mathrm{O}_{3}$ generated when discharge capacity is only 5 pC. The density of $\mathrm{O}_{3}$ is nearly proportion to both discharge strength and density. And the density of NOx including $\mathrm{NO}$ and $\mathrm{NO}_{2}$ only becomes twice as discharge strength increases to 10 times. The density of NOx is nonlinear to discharge density. It shows that NOx is insensitive to discharge strength and density. The ratio of [NO] and [NO] decreases with discharge density. However it does not change too much as discharge strength increases.

3) Influence of Gas Temperature

In this part, the impact of gas temperature is studied. The discharge strength Pc, the discharge time Td, Gas pressure P and discharge area S are assumed to be $500 \mathrm{pC}, 2 \mathrm{~ms}, 1 \mathrm{~atm}$ and $2 \mathrm{~mm}^{2}$. The gas temperature $\mathrm{T}$ is assumed to be 273,293 and $313 \mathrm{~K}$. The calculated results for residence time $t r$ equal to $1 \mathrm{~s}$ are list in table 5 . As can see from table the density of $\mathrm{O}_{3}$ and NOx show no variation as T changes. However $[\mathrm{NO}] /\left[\mathrm{NO}_{2}\right]$ does decrease as $\mathrm{T}$ increases.

Tab.5 Influence of Gas Temperature to $\mathrm{O}_{3}$ and NOx production

\begin{tabular}{c|c|c|c|c|c|c}
\hline Serial No. & $\mathrm{T}(\mathrm{K})$ & $\mathrm{cO}_{3}(\mathrm{ppmv})$ & $\mathrm{cNO}_{\mathrm{x}}(\mathrm{ppmv})$ & $\mathrm{cNO}(\mathrm{ppmv})$ & $\mathrm{cNO}_{2}(\mathrm{ppmv})$ & $\mathrm{cNO} / \mathrm{cNO}_{2}$ \\
\hline 1 & 273 & 1.01 & 0.0293 & 0.0176 & 0.0117 & 1.5 \\
\hline 2 & 293 & 1.01 & 0.0293 & 0.0169 & 0.0124 & 1.36 \\
\hline 3 & 313 & 1.01 & 0.0293 & 0.0162 & 0.0131 & 1.24 \\
\hline
\end{tabular}

4) Influence of Gas Pressure

In this part, the impact of gas pressure is studied. The discharge strength Pc, the discharge time Td, gas temperature T and discharge area S are assumed to be $500 \mathrm{pC}, 2 \mathrm{~ms}, 293 \mathrm{~K}$ and $2 \mathrm{~mm}^{2}$. The Gas pressure P is assumed to be 0.9, 0.95 and $1 \mathrm{~atm}$. The calculated results for residence time $t r$ equal to $1 \mathrm{~s}$ are list in table 6 . As can see from table the density of $\mathrm{O}_{3}$ and $\mathrm{NOx}$ show no variation as $\mathrm{P}$ changes. However $[\mathrm{NO}] /\left[\mathrm{NO}_{2}\right]$ does decrease as $\mathrm{P}$ increases.

Tab.6 Influence of Gas Pressure to $\mathrm{O}_{3}$ and NOx production

\begin{tabular}{c|c|c|c|c|c|c}
\hline Serial No. & $\mathrm{P}(\mathrm{atm})$ & $\mathrm{cO}_{3}(\mathrm{ppmv})$ & $\mathrm{cNO}_{\mathrm{x}}(\mathrm{ppmv})$ & $\mathrm{cNO}(\mathrm{ppmv})$ & $\mathrm{cNO}_{2}(\mathrm{ppmv})$ & $\mathrm{cNO} / \mathrm{cNO}_{2}$ \\
\hline 1 & 0.9 & 1.01 & 0.0293 & 0.0172 & 0.0121 & 1.42 \\
\hline 2 & 0.95 & 1.01 & 0.0293 & 0.0171 & 0.0122 & 1.4 \\
\hline 3 & 1 & 1.01 & 0.0293 & 0.0169 & 0.0124 & 1.36 \\
\hline
\end{tabular}




\section{Conclusion}

In this paper, a new discharge diagnostic method-decomposition gas analysis method based on air by-products, ozone and $\mathrm{NO}_{\mathrm{x}}$, is proposed. The density of $\mathrm{O}_{3}$ and $\mathrm{NO}_{\mathrm{x}}$ near the discharge area is calculated based on reaction kinetics theory. Some results are obtained based on the calculations.

1) When discharge capacity is less than about $100 \mathrm{pC}$ the production of $\mathrm{O}_{3}$ and $\mathrm{NO}_{\mathrm{x}}$ is in the same order. When discharge capacity increases, $\mathrm{O}_{3}$ becomes the main by-product under discharge. $\mathrm{NO}_{\mathrm{x}}$ is less than $1 \%$ of $\mathrm{O}_{3}$ when discharge capacity is about $10000 \mathrm{pC}$. Among $\mathrm{NO}_{\mathrm{x}}$ which includes $\mathrm{NO}, \mathrm{NO}_{2}, \mathrm{NO}_{3}$ and $\mathrm{N}_{2} \mathrm{O}_{5}, \mathrm{NO}$ and $\mathrm{NO}_{2}$ are much more than $\mathrm{NO}_{3}$ and $\mathrm{N}_{2} \mathrm{O}_{5}$.

2) There are 16ppbv of $\mathrm{O}_{3}$ generated when discharge is only about $5 \mathrm{pC}$. The density of $\mathrm{O}_{3}$ increases linearly with discharge strength and density. The density of $\mathrm{NO}_{\mathrm{x}}$ increases nonlinearly.

3) Both gas temperature $\mathrm{T}$ and pressure $\mathrm{P}$ have little impact on the density of $\mathrm{O}_{3}$ and $\mathrm{NO}_{\mathrm{x}}$. However the $[\mathrm{NO}] /\left[\mathrm{NO}_{2}\right]$ does decrease as $\mathrm{P}$ and $\mathrm{T}$ increases.

\section{Acknowledgement}

This work has been financed by the Research Fund of CAS and Nature Science Foundation of China(No.51307157). The authors also gratefully acknowledge Pro. Han Li, Dr. Lin Tao and Dr. Han Dong for helpful discussions.

\section{References}

[1] ZHANG Xiaoxing, LIU Heng, ZHANG Ying, LIU Zhe, LI xin. Quantum detection of trace acetylene gas based on the peak area of photoacoustic spectroscopy[J]. High Voltage Engnieering, 2015, 41(3): 857-863.

[2] ZHOU Wenjun, QIAO Shengya, LI Li. WANG Baoshan, HU Hui, LUO Yunbai. Creeping discharge monitoring of epoxy space in GIS using a new target Gas CS2[J]. High Voltage Engnieering, 2015, 41(3):848-856.

[3] L.Lepine, Denise Lessard-Deziel, Mario Belec, Calogero Guddemi and Duc Ngoc Nguyen. Understanding ozone distribution inside stator core and measurements inside air-cooled generators to assess partial discharges problems[C], Iris rotating ma-chine Conference, June 2007, San Antonio, Tx.

[4] C.Millet, Duc Ngoc Nguyen, L.Lepine, Denise Lessard Deziel, Mario Belec, and Calogero Guddemi. Case Study-High Ozone concentration in Hydro generators[C]. 2009 IEEE Electrical Insulation Conference, Montreal, QC, Canada, 31 May-3 June 2009.pp178-182.

[5] Kitayama J, Kuzumoto $M$. Theoretical and experimental study on ozone generation characteristics of an oxygen-fed ozone generator in silent discharge[J]. Journal of Physics D Applied Physics, 1997, 30(17): 2453-2461(9).

[6] S.Yagi, M. Tanaka. Mechanism of ozone generation in air-fed ozonizers[J]. Journal of Physics D Applied Physics, 1979, 12: 1509-1520.

[7] R. Peyrous. The effect of relative humidity on ozone production by corona discharge in Oxygen or air - a numerical simulation - part I: oxygen[J]. Ozone: Science \& Engineering, 1990, 12(1): $19-40$.

[8] R. Peyrous. The effect of relative humidity on ozone production by corona discharge in Oxygen or air - a numerical simulation - part I: air[J]. Ozone: Science \& Engineering, 1990, 12(1): 41-64.

[9] Junhong Chen, Jane H. Davidson. Ozone production in the positive DC corona Discharge: model and comparison to experiments[J]. Plasma Chemistry and Plasma Processing, 2002, 22(4): 495-522. 